\section{Reactions of male fighters to male and female mice, untreated or deodorized ${ }^{* \dagger}$}

\author{
C. T. LEE and S. C. BRAKE
}

The University of Texas at Austin, Austin, Tex. 78712

Four experiments were performed to investigate the male mouse fighter's reaction toward mature male and female mice. The first two experiments showed that normal DBA and blind SJL fighters were able to make differential reactions; they were more aggressive toward males than females. Thus, it was hypothesized that olfactory cues were responsible for this differential reaction. Experiment 3 partly substantiated the hypothesis by showing that a deodorant, Man-power, reduced DBA fighters' reactions to males, while another deodorant, Pristeen, did not alter the fighters' behavior. Experiment 4 showed that fighters were more aggressive toward sham-operated males than toward castrated males, thus suggesting that male hormone, androgen, might produce pheromone to evoke the aggressive tendency in fighters.

The intersex agonistic interaction is one of the important paradigms for investigating the communicatory mechanisms between animals of opposite sexes. However, a review of the literature does not reveal good empirical studies on agonistic interactions between male and female mice (Scott \& Fredericson, 1951; Scott, 1966). The present series of experiments was designed to study (1) the possible differential reactions of trained male mouse fighters to mature male and female mice, and (2) the underlying mechanisms responsible for the differential reaction, if there is one.

\section{EXPERIMENT} Subjects

Eight male DBA/2J (DBA) inbred mice with normal sensory capacities were trained as fighters. They were purchased from Jackson Laboratory at 6 weeks of age. Upon arrival, the mice were housed singly. They were trained to fight at 16 weeks of age and were tested at the beginning of the experiment, when they were 25 weeks old.

Eight each of mature male and female $\mathrm{A} / \mathrm{J}$ mice, approximately 17 weeks of age, were tested. All animals were maintained with free access to food and water, except during testing periods.

\section{Apparatus}

A living quarter consisting of two

* Supported by National Science Foundation-University science Development Program Grant GU-1598. Part of these works has been presented at the 11 th annual meeting of Psychonomic Society, 1970, and at the 137 th meeting of American Association for the A Dvancement of Science. The authors wish to thank Daniel Q. Estep for operating the mice.

tRequests for reprints should be sent to C. T. Lee, Department of Psychology Brooklyn College. The City University of New York, Brooklyn, N.Y. 11210. compartments, each measuring $18 \times 18 \times 18$ in., was used to test the animals. There was a hole in the partition, allowing the mice to enter each compartment. Two stopwatches were used for recording latencies of a hand counter was used to record the number of attacks.

\section{Procedure}

Training fighters. The mouse was trained to fight with a combination of the dangling method and the latency method (Scott, 1966). It was given 20 daily trials of training with the dangling method. After the last trial of

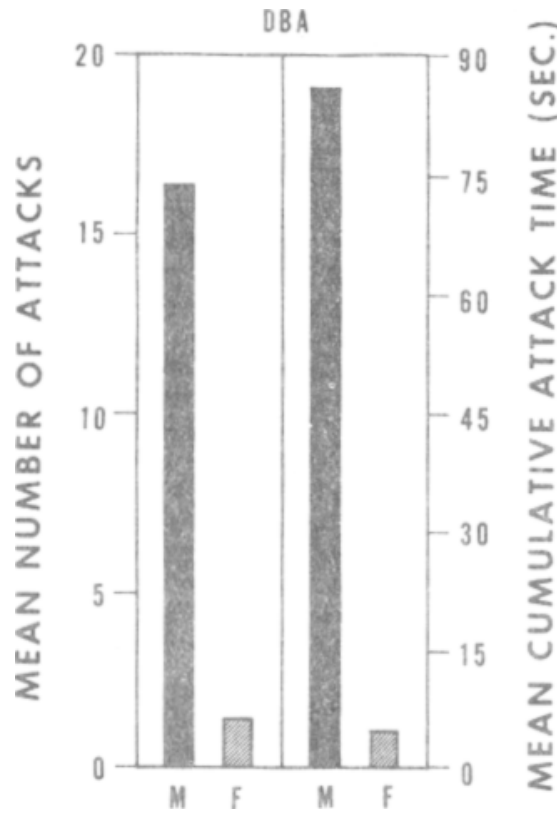

Fig. 1. The mean number of attacks exhibited by DBA fighters to mature males $(M)$ and females $(F)$. attack and cumulative attack time, and and the mean cumulative attack time training, a passive mouse was released in the fighting compartment next to the $S$ for a maximum of $3 \mathrm{~min}$. The latency of the first attack received by the passive mouse was recorded. As soon as the attack occurred, the mice were separated. The training lasted for 6 days. At the end of the training, all inghters reached the criterion of attacking a passive mouse within $3 \mathrm{~min}$.

Experiment proper. Three days before testing, the fighter was given 10 trials of training with the dangling method and then released in the living quarter, which contained a nesting box and nesting materials. Food, water, and the nesting box and materials were removed before a $S$ was placed in the compartment opposite to the one occupied by the fighter. The social encounters were observed for $30 \mathrm{~min}$ after the first attack took place. The latency of the first attack, the total number of attacks, and the cumulative time of attack were recorded. In addition to these measures, the social interactions between the animals were also described. If there were no fights observed in $30 \mathrm{~min}$, the $S$ was removed.

On the first testing session, half of the fighters were tested with males and the other half with females. The testing order was reversed on the second session. There was 1 day in between these two sessions. The bedding, nesting materials, food, and water were changed before a new fighter was tested.

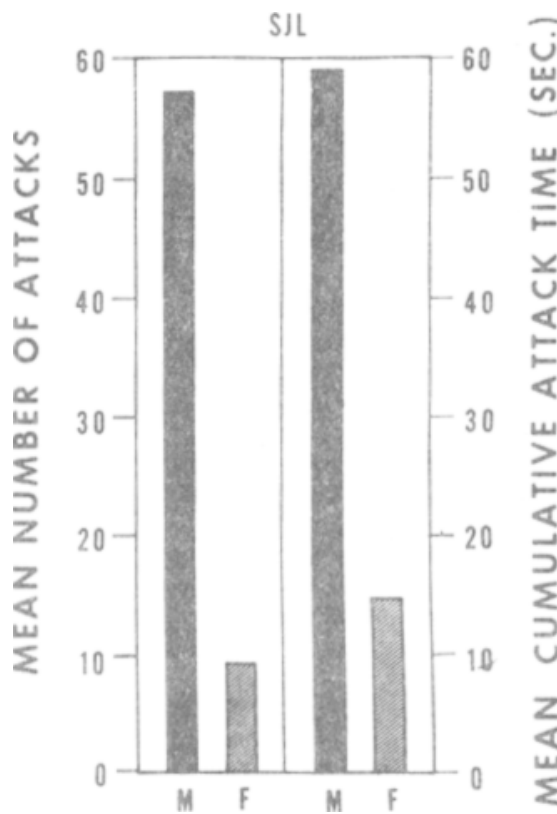

Fig. 2. The mean number of attacks and the mean cumulative attack time exhibited by SJL blind fighters to mature males (M) and females (F). 

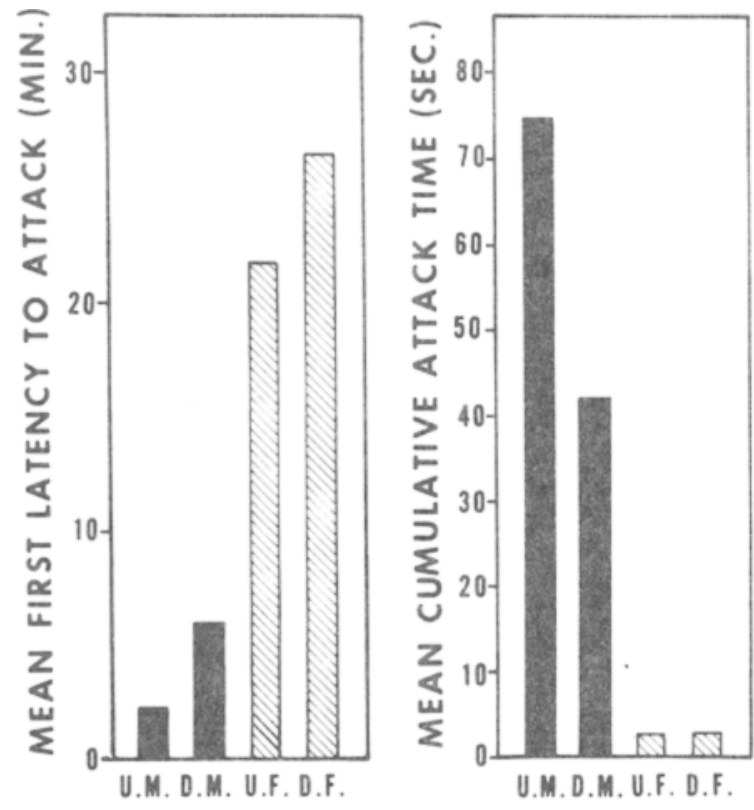

\section{U.M. = UNTREATED MALE D.M. $=$ DEODORIZED MALE}

Fig. 3. The reactions of DBA fighters to untreated or deodorized males or females expressed in three measures.

Results and Discussion

Figure 1 shows the mean number of attacks and the mean cumulative at ack time. The Wilcoxon matched-pair signed-ranks test indicated that DBA fighters attacked mature males more often than females $(\mathrm{T}=0, \mathrm{p}<.01)$. In five out of the eight cases, the fighters did not attack the females at all. The fighters also attacked males for a longer period of time than they did females $(T=0$, $p<.01)$. Thus, the trained fighters were apparently more aggressive toward males than females. This is in agreement with Kahn's (1954) observation that it was rather hard to train male mouse fighters to attack female mice.

The differential responses of the DBA fighters may be due to the information received through olfactory, visual, or auditory senses. Since the mouse does not vocalize very much under normal circumstances, the visual and olfactory cues may be more important: observation revealed that the fighters frequently sniffed the facial and genital areas of the Ss during the social encounters. Hence, the olfactory cues may be the major factors responsible for the differential reactions of the fighters. Experiment 2 was designed to investigate this problem.

\section{EXPERIMENT 2}

To compare the importance of olfactory and visual cues under a fighting situation, genetically blind

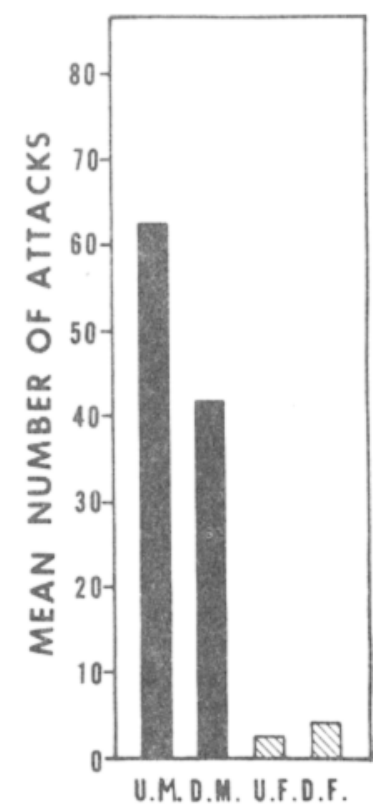

\section{U.F. = UNTREATED FEMALE D.F. $=$ DEODORIZED FEMALE}

mice, SJL/J (SJL), were trained to be fighters and tested in the same manner as DBA fighters. If the olfactory information is more important than visual, the SJL fighters should behave very much like the DBA.

Subjects

Eight male SJL/J mice were trained

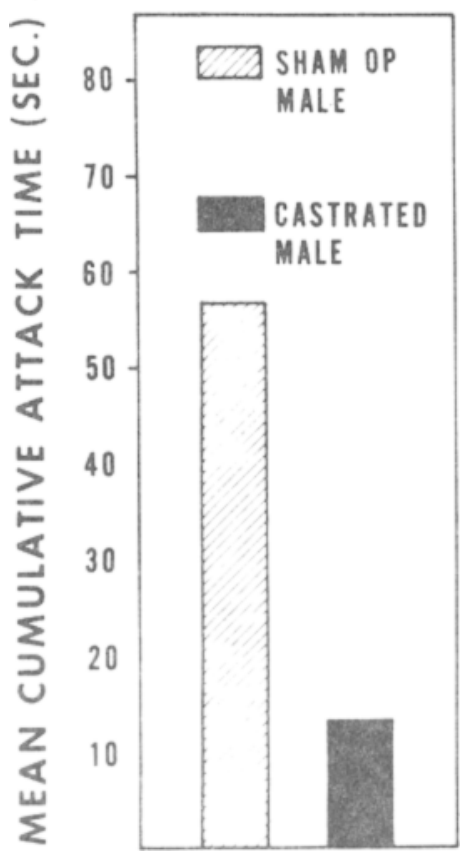

to fight at 18 weeks of age and tested at 28 weeks of age. Eight each of male and female $\mathrm{A} / \mathrm{J}$ mice were tested at the age of 13 weeks. The animals were maintained under the same conditions as in Experiment 1.

Apparatus and Procedure

Apparatus and procedure were the same as those used in Experiment 1. Results and Discussion

Figure 2 shows that the SJL indeed behaved very much like DBA fighters.

They were able to make differential attacks to male and female Ss. They attacked males longer $(T=0, p<.01)$ and more often than females $(\mathrm{T}=1$, $\mathrm{p}<.01)$. Observation again showed that the SJL fighters engaged in making facial contacts and sniffing the genital areas of the Ss.

Based on the results of these two experiments, it is apparent that the trained mouse fighters are able to make distinctions between males and females under a fighting situation, and the discrimination is primarily based on olfactory information. EXPERIMENT, 3

To investigate further the function of olfactory cues, the DBA fighters were tested with mature mice sprayed with deodorants and with untreated mice. This provides a means to study the effects of masking the original odor or pheromones on fighters' behavior.

Subjects

The fighters were those used in Experiment 1 . The Ss were 16 each of male and female $A / J$ mice, approximately 17 weeks of age.

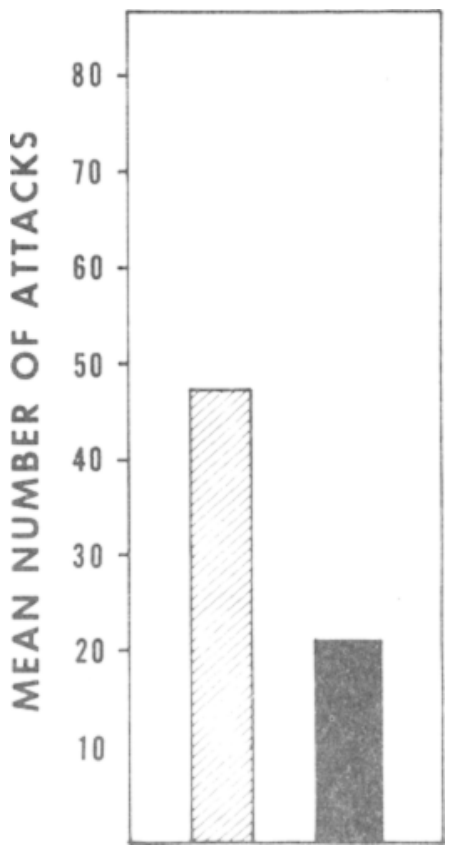

Fig. 4. The reactions of DBA fighters to sham-operated (Sham Op) or castrated males expressed in two measures. 
Apparatus

Man-power and Pristeen, commerical deodorants, were used to spray males and females, respectively. The deodorants provide distinct masking odors.

Procedure

The Ss were tested in the same manner as in Experiment 1. The male mice were tested 2 weeks before the females. On the first day of testing, half of the fighters received untreated mice and the other half received mice sprayed with the deodorant $10 \mathrm{~min}$ before testing. On the second testing session, the order was reversed. Results and Discussion

Figure 3 shows that the fighters attacked untreated males sooner than they did the deodorized males ( $T=0$, $p<.01$ ); however, there were no differences in responding to untreated or deodorized females. It is interesting to note that the fighters reacted to deodorized males with hyperactivity such as frantic running around the living quarter after sniffing at the Ss.

The central and the right portions of the figure indicate that the untreated males were attacked longer $(T=3, p<.01)$, but not more often than the deodorized ones. Characteristically, the deodorized males received attacks of very brief episodes. The fighters did not make differential agonistic reactions to untreated or deodorized females. The fact that the deodorants produce different results in males and females may be due to different deodorants used. Further research needs to be done to clarify this issue. However, it is very conclusive that one of the deodorants, Man-power, was able to affect the fighters' reaction to male mice, and the effect was possibly produced by olfactory cues.

\section{EXPERIMENT 4}

It is possible that the olfactory cues emitted by the males and the females may be related to sex hormones. The female pheromone may have an inhibitory function on aggressive behavior, and the male pheromone may have a releasing function. The latter possibility was entertained by Mugford \& Nowell (1970a, b), who have recently suggested that androgen is responsible for the production of male pheromone in the urine. If this is the case, it could be expected that the castrated male mice should evoke less aggressive behavior from fighters, as compared with sham-operated mice, for after castration the output of androgen will diminish and hence alter the intensity or the contents of male pheromone.

\section{Subjects}

The DBA fighters were used again. Sixteen C57BL/6J male mice were used. Half of them were castrated and half of them sham-operated. Procedure

Three weeks after the operation, the mice were tested according to the design used in Experiment 1.

Results and Discussion

Figure 4 indicates that the castrates were not attacked as long nor as often as the sham-operated mice $(T=0$, $\mathrm{p}<.01$ for both measures). This is a very interesting result, since Beeman (1947) also reported that castration retarded the development of aggressive behavior in mice. Thus, the androgen may have dual functions in relation to aggression: (1) it is a necessary condition for the development of aggressive behavior and (2) it also produces pheromone to evoke the aggressive tendency in fighters. The second function was also proposed by Mugford \& Nowell (1970a, b).

\section{REFERENCES}

BEEMAN, E. A. The effect of male hormone on aggressive behavior in mice. Physiological Zoology, 1947, 20, 373-405.

KAHN M, $W$. Infantile experience and mature aggressive behavior of mice; some maternal influences. Journal of Genetic Psychology, 1954, 84, 65-76.

MUGFORD, $R$ A \& NOWELL, N. W. The aggression of male mice against androgenized females. Psychonomic Science, 1970a, 20, 191-192.

MUGFORD, R. A., \& NOWELL, N.W. Pheromones and their effect on aggression in mice. Nature, $1970 \mathrm{~b}, 226$, 967-968.

SCOTT, J. P., \& FREDERICSON, E. The causes of fighting in mice and rats. Physiological Zoology, 1951, 24, 273-309.

SCOTT, J. $P_{\text {. }}$, Agonistic behavior of mice and rats: A review. American Zoologist, 1966. 6, 683-701. 